\title{
Обзорная статья
}

\section{Геотермия и сейсмичность Кавказского региона и обратная залача геоАинамики}

\author{
В. Б. Свалова (D), К. Ф.-М. н. \\ Институт геоэкологии им. Е. М. Сергеева РАН, Россия, 101000, Москва, \\ Уланский переулок, 13, к. 2, e-mail: v-svalova@mail. ru \\ Статья поступила: 23 июля 2019, доработана: 18 сентября 2019, одобрена в печать: 24 сентября 2019.
}

Аннотация: Актуальность работы. Проблема формирования и эволюции геологических структур является одной из важнейших в тектонике и геодинамике. Связь поверхностных структур с глубинными движениями в литосффере и астеносфере всегда остается в центре исследований геологов и геосизиков. Объектом исследования является геодинамика Кавказского региона, являющегося сложной высоконапряженной геодинамической структурой, характеризующейся повышенным тепловым потоком, высокой сейсмичностью, магматизмом и вулканизмом. Геодинамика Кавказского региона определяется коллизией Евразийской и Аравийской литосфрерных плит, а также сложной историей развития Альпийско-Гималайского пояса. С точки зрения глубинной геодинамики Кавказ входит в одну из наиболее активных зон коллизии литосферных плит, характеризующихся значительными скоростями горизонтальных и вертикальных движений. Цель работы - установление условий формирования и эволюции геологических структур в различных сложных геодинамических обстановках. Методы исследования: механико математическое моделирование, геолого геодинамическая реконструкция, сейсмотомография. Решение задачи анализируется на примере геодинамики Кавказского региона. Результаты механико-математического моделирования хорошо подтверждаются данными геолого-геодинамической реконструкции и сейсмотомографиии. Механико-математическое моделирование дает возможность изучать эволюцию геологической структуры в динамике, в то время как геофизика и сейсмотомография дают глубинный разрез слоев в настоящий момент времени. Результаты работы. Разработано решение обратной задачи геодинамики прямым методом. Решена первая обратная задача геодинамики - восстановление полей скоростей, давлений и напряжений на глубине литосфреры по имеющимся данным о скоростях на дневной поверхности. Поставлена и решена вторая обратная задача геодинамики - определение движения границ на глубине литосферы по заданным движениям дневной поверхности. Практическая значимость работы. Полученные решения могут использоваться для анализа глубинных геодинамических проблем, а совместно с геотермическим моделированием, геолого-геофизическими методами и сейсмотомограсрией могут служить надежным аппаратом изучения глубинной геодинамики в связи с формированием и эволюцией геологических структур. Сравнительный анализ различных подходов и решений дает возможность с большей надежностью делать выводы о глубинных механизмах движений и их проявлении на поверхности Земли и обосновать наиболее вероятные причины формирования и эволюции различных геологических структур и процессов. фрия.

Ключевые слова: геотермия, сейсмичность, геодинамика, Кавказ, моделирование, сейсмотомогра-

Благодарности: Работа выполнена при поддержке гранта Российского научного фонда (проект №19-47-02010, «Natural hazards and monitoring for mountain territories in Russia and India») и темы HИР (№0142-2014-0027 «Развитие теории и методов изучения новейшей тектоники и современной геодинамики платформенных и орогенных территорий применительно к оценке их безопасности»).

Для цитирования: Свалова В.Б. Геотермия и сейсмичность Кавказского региона и обратная задача геодинамики. Геология и Геофизика Юга России. 2019. 9 (3): 77-93. DOI: 10.23671/VNC. 2019.3.36485. 


\title{
Review
}

\section{Geothermics and seismicity of the Caucasus region and inverse problem of geodynamics}

\author{
V.B. Svalova \\ Sergeev Institute of Environmental Geoscience, Russian Academy of Sciences, 13 \\ Ulansky pereulok building 2, Moscow 101000, Russian Federation, \\ e-mail: v-svalova@mail.ru
}

Received 23 July 2019; revised 18 September 2019; accepted 24 September 2019.

\begin{abstract}
Relevance. The problem of the formation and evolution of geological structures is one of the most important in tectonics and geodynamics. Interrelation of surface structures and deep movements in the lithosphere and asthenosphere always is in the focus of geologists ' and geophysicists' research. The object of the study is the geodynamics of the Caucasus region characterized by increased heat flow, high seismicity, magmatism and volcanism. The geodynamics of the region is caused by the collision of the Eurasian and Arabian lithospheric plates, as well as the complex history of the Alpine-Himalayan belt evolution. In the context of a deep geodynamics, the Caucasus is one of the most active zones of collision of lithospheric plates, characterized by significant speeds of horizontal and vertical movements. Aim. Identification of the conditions for the formation and evolution of geological structures in various complex geodynamic settings. Methods: mechanical and mathematical modeling, geological and geodynamic reconstruction, seismotomography. The problem solution is analyzed by the example of geodynamics of the Caucasus region. The results of mechanical and mathematical modeling are well confirmed by the data of geological and geodynamic reconstruction and seismotomography. Mechano-mathematical modeling makes it possible to study the evolution of a geological structure in dynamics, while geophysics and seismotomography give a deep section of the strata in the present state. Results. A solution of geodynamics inverse problem by the direct method is developed. The first inverse problem of geodynamics (the restoration of the velocity, pressure and stress fields at the depth of the lithosphere from the available data on the velocities on the day surface) is solved. The second inverse problem of geodynamics (the determination of the movement of boundaries at the depth of the lithosphere by the given movements of the day surface) is posed and solved. Practical significance. The obtained solutions can be used for the analysis of deep geodynamic problems; and together with geothermal modeling, geological and geophysical methods and seismotomography they can serve as a reliable instrument for studying deep geodynamics in connection with the formation and evolution of geological structures. A comparative analysis of various approaches and solutions makes it possible to draw more reliable conclusions about the underlying mechanisms of movements and their manifestation on the Earth's surface; it can also explain the most probable reasons for the formation and evolution of various geological structures and processes.
\end{abstract}

Keywords: geothermy, seismicity, geodynamics, Caucasus, modeling, seismic tomography.

Acknowledgments: This work was supported by a grant from the Russian Science Foundation, (project No. 19-47-02010, "Natural hazards and monitoring for research in Russia and India") and research topics (No. 0142-2014-0027 "Development of the theory and methods of studying the latest tectonics and modern geodynamics of platform and orogenic territories in relation to the assessment of their safety").

For citation: Svalova V.B. Geothermics and seismicity of the Caucasus region and inverse problem of geodynamics. Geologiya i Geofizika Yuga Rossii = Geology and Geophysics of Russian South. 2019. 9(3): 77-93. (In Russ.) DOl: 10.23671/VNC.2019.3.36485.

\section{1. Введение}

Проблема формирования и эволюции геологических структур является одной из важнейших в тектонике и геодинамике. Связь поверхностных структур с глубинными движениями в литосфере и астеносфере всегда остается в центре исследований геологов и геофизиков. 
Анализ геолого-геофизических данных по развитию Кавказского региона в рамках Альпийско-Гималайского пояса приводит к выводу, что Кавказ может рассматриваться как один из наиболее напряженных и геодинамически активных сегментов глобальной структуры, характеризующийся повышенным тепловым потоком, высокой сейсмичностью, магматизмом и вулканизмом [Гончаров и др., 2015; Милюков и др., 2015; Svalova et al., 2019; Уломов и др., 2007], (рис. 1, 2).

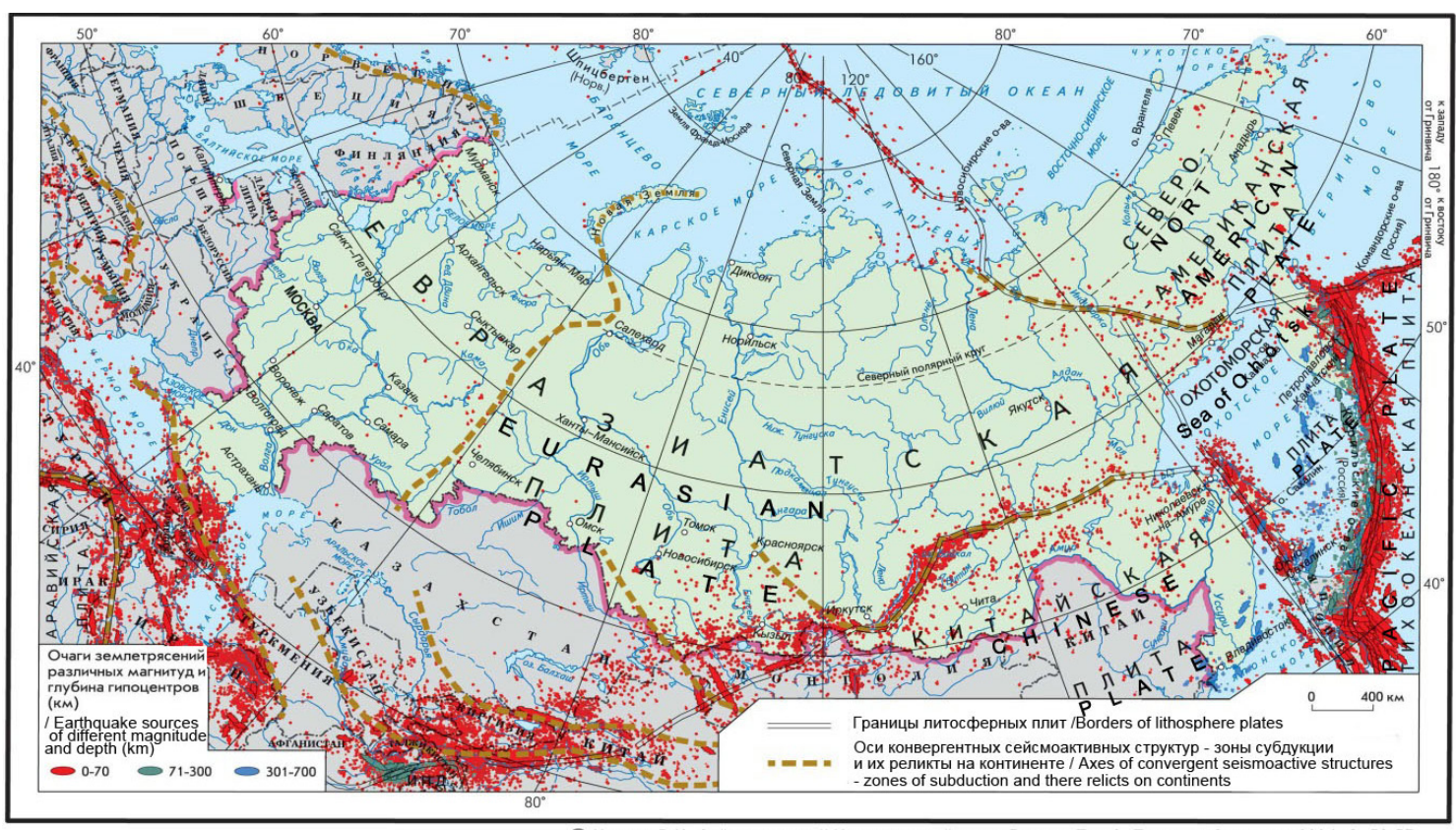

(C) Уломов В.И. Сейсмичность // Национальный атлас России. Том 2. Природа. Экология. 2004. С. 56-57.

Рис. 1. Карта сейсмичности России и сопредельных территорий. Автор Уломов В. И. / Fig. 1. Map of the seismicity of Russia and adjacent territories. Author Ulomov V.I.

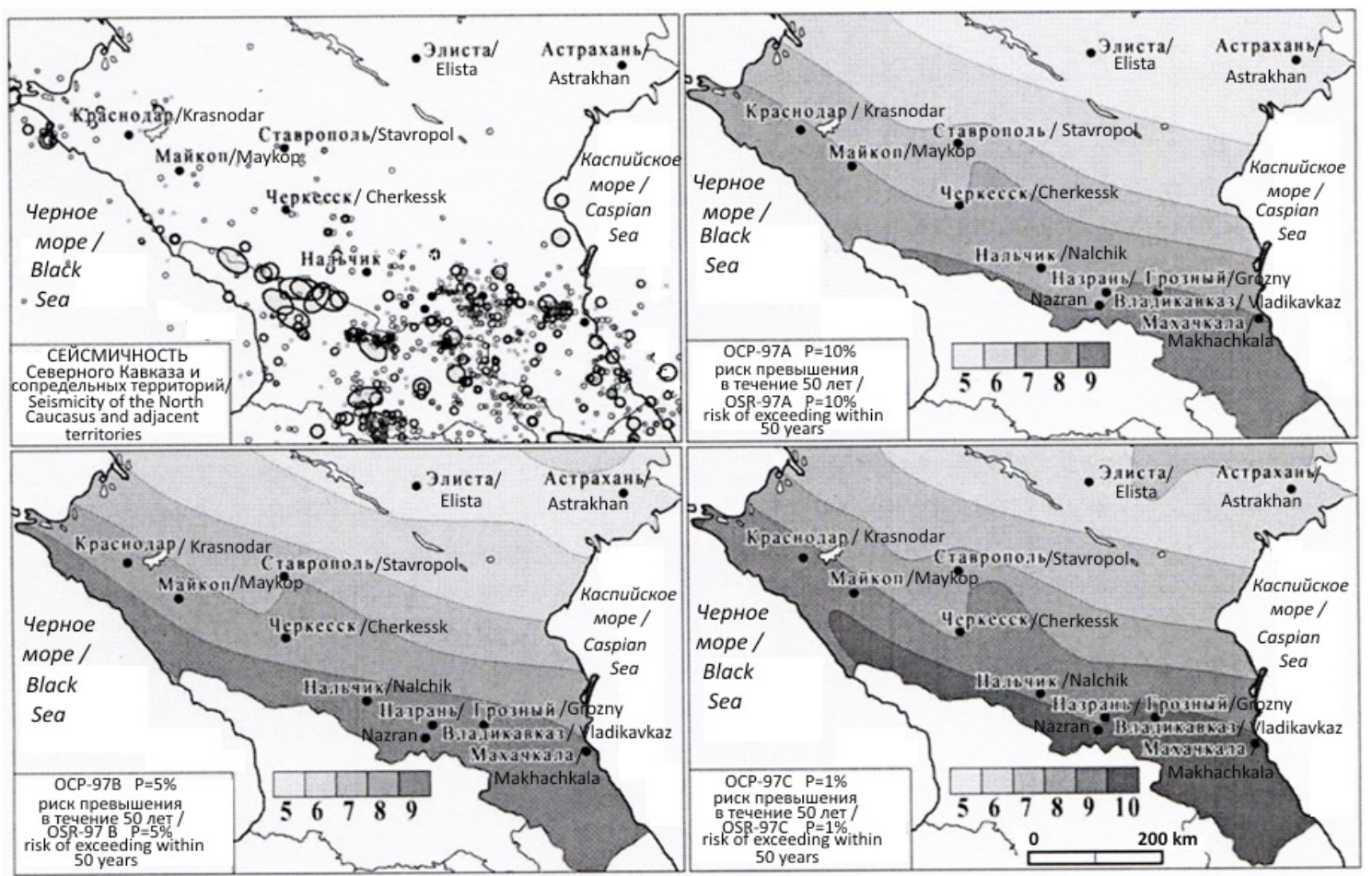

Рис. 2. Сейсмичность Кавказа и фрагменты карт ОСР-97 - общего сейсмического районирования Российской Федерации. На карте сейсмичности эллипсами изображены очаги землетрясений 
с $M=6,8$ и более, кружками - от $M=6,7$ до $M=3,5$. На картах ОСР-97 (A, B, C) показаны зонь разной сейсмической интенсивности (в баллах), в пределах которых допускается превышение сейсмического эффекта в течение 50-тилетних интервалов времени с различной вероятностью10\%, 5\% и 1\%, соответственно [Уломов и др., 2007]. /

Fig. 2. Seismicity of the Caucasus and fragments of maps OSR-97 - the general seismic zoning of the Russian Federation. On the seismicity map, the ellipses show the sources of earthquakes with $M=6.8$ or more, circles - from $M=6.7$ to $M=3.5$. On the maps OSR-97 (A, B, C) zones of different seismic intensity (in points) are shown, within which the seismic effect can be exceeded for 50-year intervals with different probabilities $-10 \%, 5 \%$ and $1 \%$, respectively [Ulomov et al., 2007].

\section{2. Геолинамика Кавказского региона}

С точки зрения глубинной геодинамики Кавказ входит в одну из наиболее активных зон коллизии литосферных плит, характеризующихся значительными скоростями горизонтальных и вертикальных движений (рис. 3).

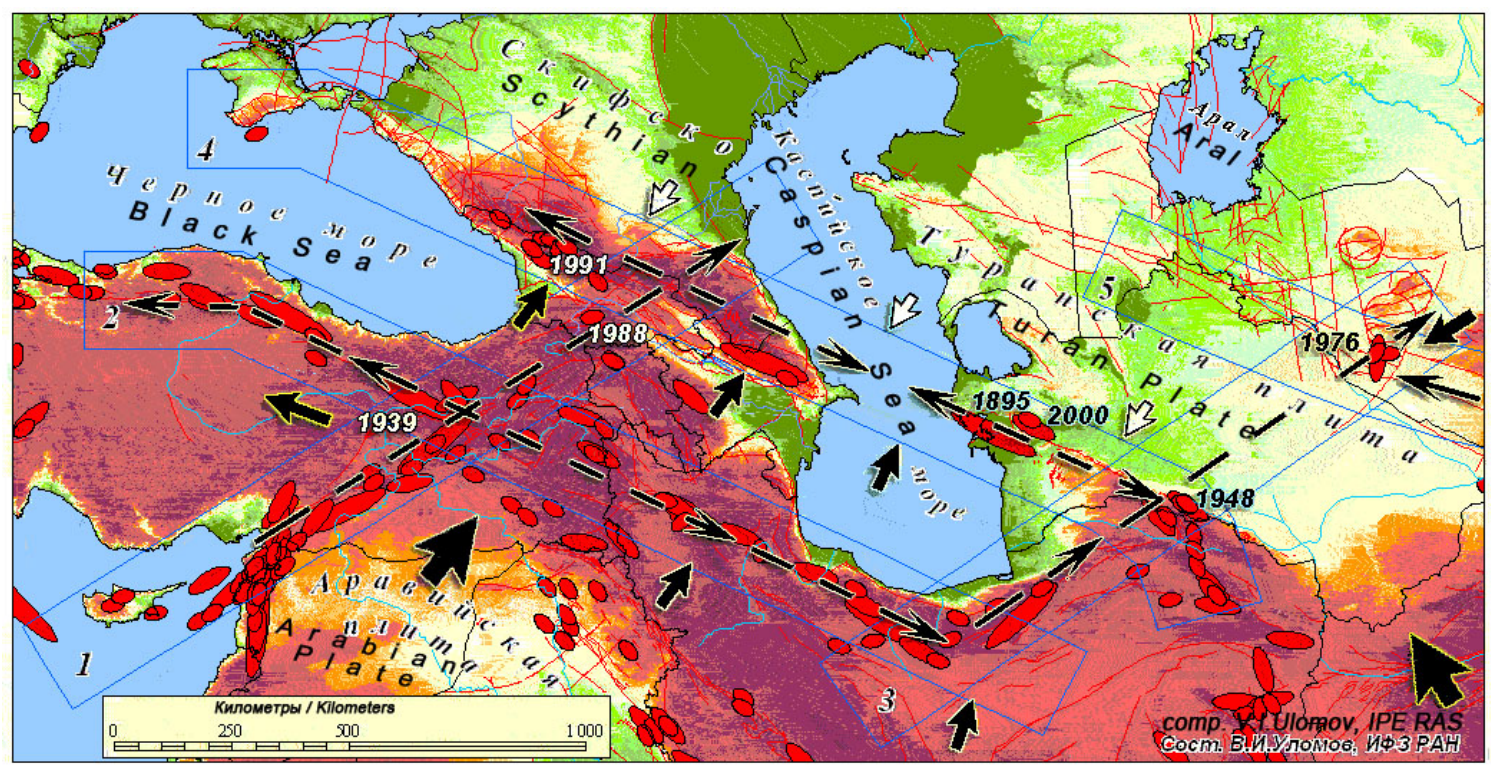

Рис. 3. Геодинамика Кавказского региона. Черными стрелками указано направление перемещения различных структур, бельли - реакция Скифско-Туранской платформы на сжимаюшие усилия со стороны Аравийской литосферной плиты (крупная стрелка) и альпийских структур Иран -

Кавказ - Анатолийского региона. Профили (полосы): 1 - Кипр - Кавказ, протяженность 1870 км; 2 - Анатолия - Эльбурс, 2270 км: 3 - Эльбурс - Туран, 1520 км; 4 - Крылм - Копетдаг, 2500 км; 5 - Южный Тянь-Шань, 2520 км. Около некоторых из очагов проставлены даты их проявления.

Черным иветом закрашены очаги землетрясений, произошедших позже 1900 г. [Уломов и др., 2007]. I

Fig. 3. Geodynamics of the Caucasus region. Black arrows indicate the direction of movement of various structures, white arrows show the reaction of the Scythian-Turan platform to compressive forces from the Arabian lithosphere plate (large arrow) and alpine structures Iran-Caucasus-Anatolia region. Profiles (stripes): 1 -Cyprus - Caucasus, length 1870 km; 2 -Anatolia-Elburs, $2270 \mathrm{~km}: 3$-Elburs - Turan, 1520 km; 4-Crimea - Kopetdag, 2500 km; 5 -Southern Tien Shan, 2520 km. About some of the foci are marked with the dates of their manifestation. The foci of earthquakes that occurred later than 1900 are shaded in black [Ulomov et al., 2007].

Поле скоростей Северного Кавказа характеризуется горизонтальным смещением в северо-восточном направлении со скоростью 26-28мм/год. Относительно неподвижной Евразии выявлено общее сжатие региона со скоростью 1-2 мм/год, которое является источником современной геологической и сейсмической активности в пограничной области Кавказа и Восточно-Европейской платформы. 
Современные вертикальные движения Северо-Кавказского региона характеризуются небольшими вертикальными движениями 2,5 мм/год в равнинной части Осетии, наибольшими для региона скоростями подъема порядка 3,5-4,5 мм/год в горной части Северного Кавказа и умеренным устойчивым подъемом 2,9 мм/год в северной части северного склона Большого Кавказа. [Милюков и др., 2015].

Согласно геодинамическим представлениям, на месте Большого Кавказа 35 млн лет назад существовал глубоководный бассейн шириной около 200 км. При постепенном закрытии его борта сближались до полного столкновения около 11 млн лет назад, после чего регион стал испытывать постоянное воздымание. При сжатии вещество литосферы образовало горный пояс с толщиной коры 45-50 км и толщиной литосферы до 250 км. В дальнейшем 5-10 млн лет назад Большой Кавказ стал быстро подниматься, а на его оси возникли вулканы Эльбрус, Казбек и др. [Хаин, Ломизе, 2005].

Видимо, это связано с подъемом астеносферы вследствие сжатия и гравитационной неустойчивости. Возможно, ситуацию можно сравнить с развитием задугового спрединга, когда горячий мантийный диапир прорывается сквозь литосферу к земной поверхности и формирует задуговый бассейн [Шарков, Свалова, 1989] (рис. 4).

В структуру Альпийского пояса входят отдельные морские впадины, осадочные бассейны и горные образования. Над поднимающимися мантийными диапирами на земной поверхности могут формироваться структуры сводового поднятия, осадочного бассейна или излияния базальтов в зависимости от стадии подъема диапира и его энергетики [Свалова, 2014]. При этом между отдельными диапирами формируются зоны сжатия, ведущие к горообразованию и утолщению коры. Так впадины западного сектора Альпийско-Гималайского пояса (Альборанская, Балеарская, Тирренская, Лигурийская, Паннонская, Ионическая, Черное море, Прикаспийская, Средне- и Южно- Каспийская) можно связать с поднимающимися мантийными диапирами, а Кавказ не только с зоной коллизии литосферных плит, но и с зоной столкновения потоков литосферы от двух мантийных диапиров под впадинами Черного и Каспийского морей.

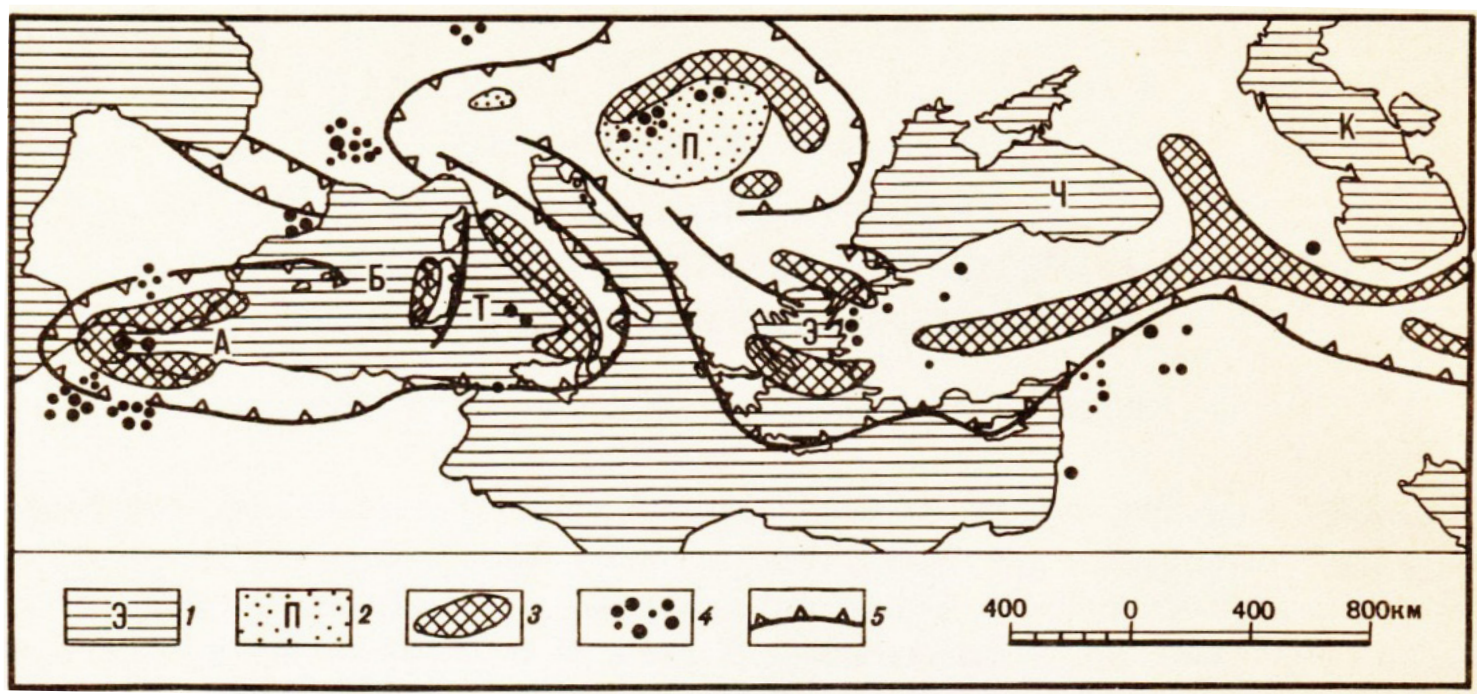

Рис. 4. Структура западной части Альпийско-Гималайского пояса. 1 -моря (А-Альборанское, ББалеарское, K-Каспийское, T-Тирренское, Ч-Черное, Э- Эгейское). 2 - Паннонская впадина. 3 - вулканические дуги. 4 - ареаль базальтового вулканизма. 5 - фронтальные зоны крупнейших надвиговых структур [Шарков, Свалова, 1989]. I

Fig. 4. The structure of the western part of the Alpine-Himalayan belt. 1 - seas (A-Alboran, BBalearic, $K$-Caspian, T-Tyrrhenian, 4 -Black, Э-Aegean). 2 - Pannonian hollow. 3 - volcanic arcs. 4 - areas of basaltic volcanism. 5 - frontal zones of the largest thrust structures [Sharkov, Svalova, 1989]. 


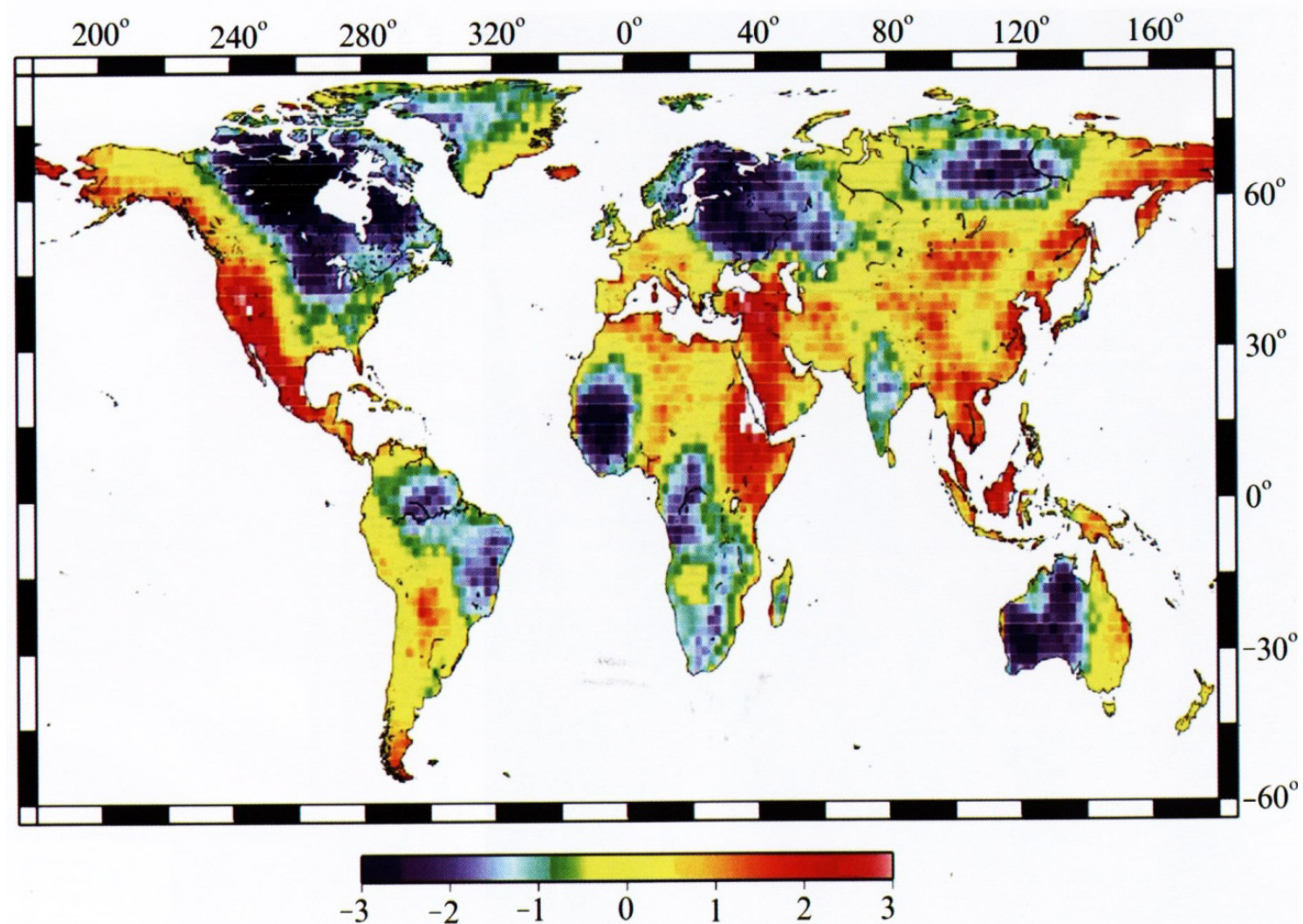

Рис. 5. Сейсмотомография латеральных неоднородностей литосферной мантии под континентами. Показаны положительные и отрицательные отклонения скорости поперечных волн. (Ж. Поупине). Максимальные скорости приурочены к древним ядрам кратонов. Кавказскому региону соответствуют минимальные скорости [Хаин, Ломизе, 2005]. 1

Fig. 5. Seismotomography of lateral heterogeneities of the lithospheric mantlebeneath the continents.

Positive and negative shear wave velocity deviations are shown. (J. Pupine). Maximum speeds are confined to the ancient craton nuclei. The Caucasus region corresponds to minimum speeds [Khain, Lomize, 2005].

Сложное напряженно-деформированное состояние литосферы Кавказа выражается в наличии разломов, трещиноватости пород, проявлении магматизма и вулканизма, высокой сейсмичности, повышенного теплового потока, гидротермальной активности, а также подтверждается данными сейсморазведки и сейсмотомографии (рис. 5,6 ).

\section{3. Геотермия Кавказского региона}

Значение плотности теплового потока является показателем геодинамической активности структур литосферы. Сравнение плотности теплового потока с мощностью земной коры дает неоднозначные результаты. Для отдельных блоков коры существует прямая связь этих параметров, для других же - обратная. Примером обратной связи может быть котловина Черного моря с тонкой земной корой. В этой структуре отмечаются низкие значения теплового потока (30-40 мВт/м²) при малой мощности земной коры [The Global Heat Flow Database...]

Другая ситуация с высоким тепловым потоком наблюдается в орогенных областях с мощной земной корой, например, в Гималаях, мегантиклинории Большого Кавказа и др. (рис. 7, 8). 


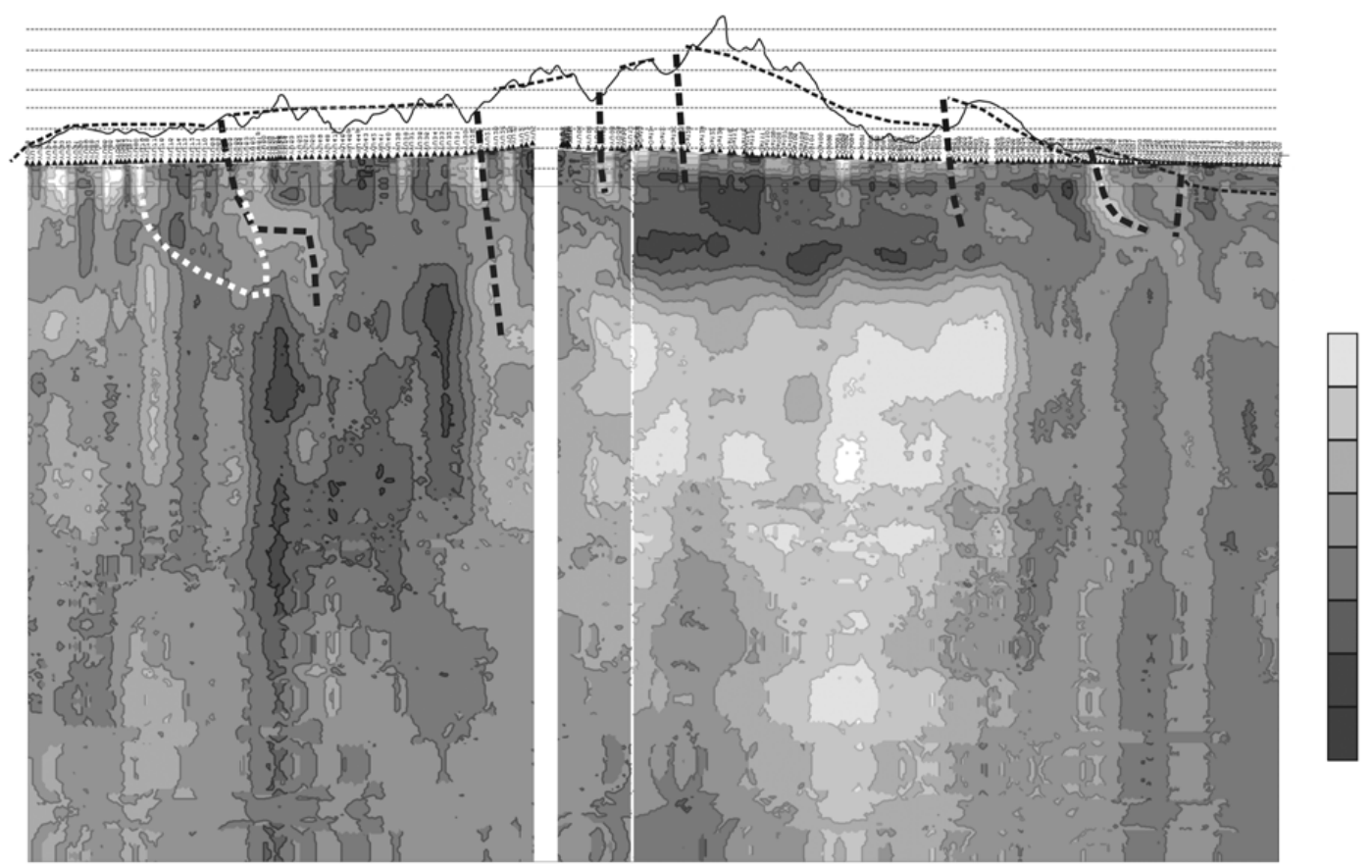

Рис. б. Профиль микросейсмического зондирования Кавказа до глубины 60 км. Фиксируется разуплотненное тело до глубины Мохо и глубже. Показаны положительные (темные) и отрицательные (светлье) отклонения скорости поперечных волн. [Рогожин и др., 2015]. /

Fig. 6. Profiles of microseismic sounding of the Caucasus to a depth of $60 \mathrm{~km}$. The decompressed body is fixed to the depth of Moho and deeper. Positive (dark) and negative (light) deviations of the shear wave velocity are shown. [Rogozhin et al., 2015].

Кавказский регион характеризуется сложным и сильно дифференцированным тепловым полем. Пониженные потоки соответствуют предгорным и межгорным прогибам, повышенные складчатым зонам. Среднее значение теплового потока для складчатой области Кавказа составляет $78 \mathrm{mBT} / \mathrm{M}^{2}$.

Характер теплового поля Кавказского региона хорошо коррелируется с особенностями его геологического строения и истории развития. Зоны складкообразования и проявления молодого вулканизма выделяются высокими тепловыми потоками. Предгорным и межгорным прогибам соответствуют в основном низкие тепловые потоки.

В прогибах значительное влияние на характер теплового поля оказывает строение осадочного чехла и структура фундамента (рис. 7,8 ).

\section{4. Обратная задача геодинамики}

Мантийный диапиризм и подъем мантийных плюмов выражают явление гравитационной неустойчивости на границе астеносфера-литосфера и особенно ярко проявляются в периоды тектоно-магматической активизации. Поднимающиеся астеносферные массы и связанные с ними потоки тепла являются ключом к пониманию процессов формирования и эволюции земной коры, а также процессов нефтегазоносности.

Движение астеносферы отражается в поверхностных геофизических полях - геотермическом, гравитационном, электромагнитном. Наличие расплавленных астеносферных масс подтверждается сейсмическими данными, в том числе сейсмотомографией.

Движение дневной поверхности над поднимающимся мантийным диапиром фиксируется сменой режимов осадконакопления и строением осадочного чехла. Подъем диапира отражается в рельефе дневной поверхности, строении фундамента и форме границ Мохо и Конрада. 


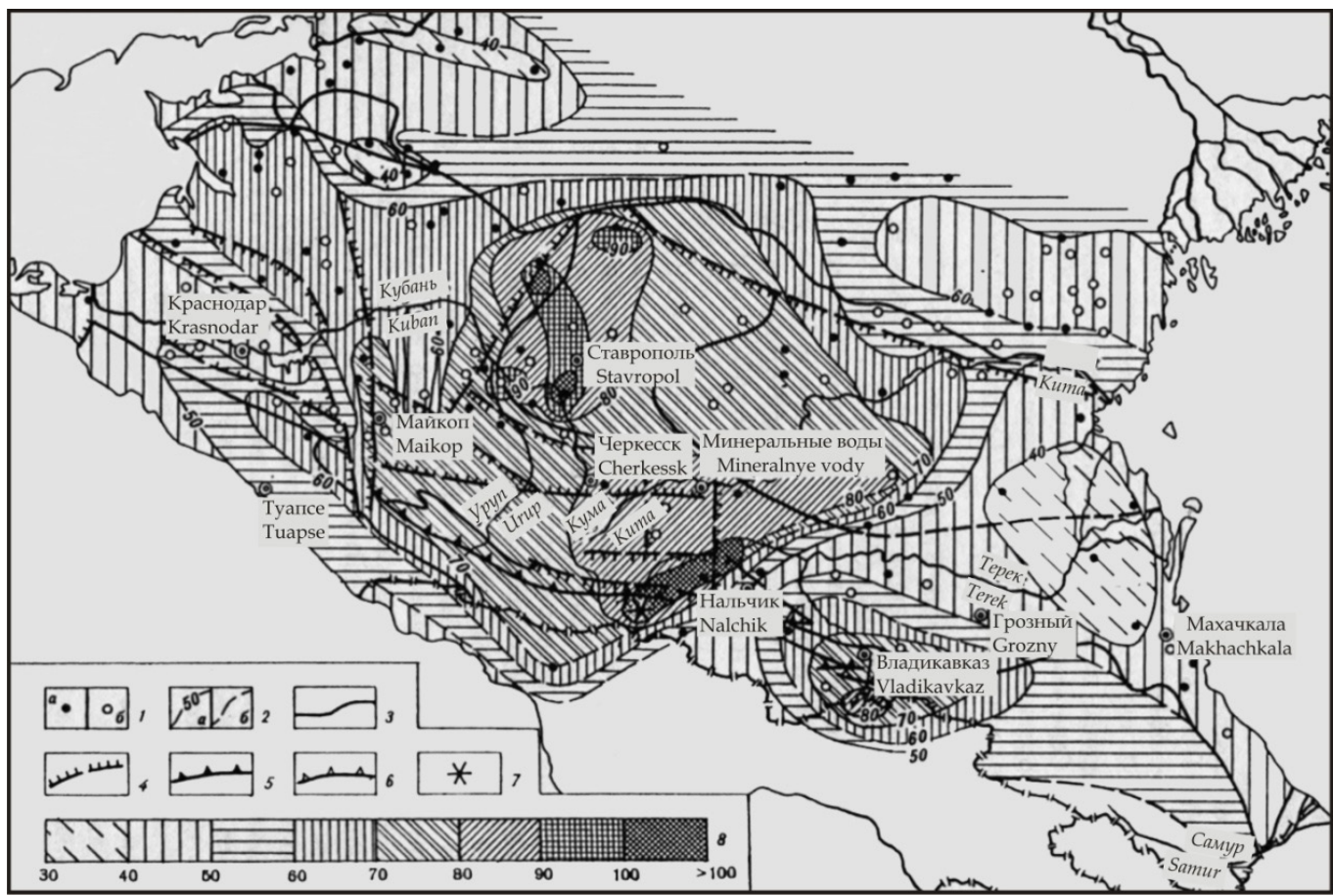

Рис. 7. Карта теплового потока Северного Кавказа. М-б 1:5000000 [Моисеенко, Негров. 1993]). 1 - станичи определения теплового потока: $a$ - единичные, $\sigma$ - групповые; 2 - изолинии теплового

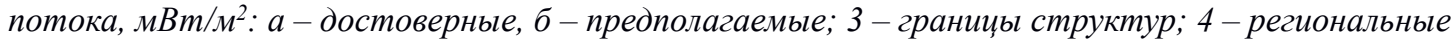
разломы; 5 - Тырнылауская шовная зона; 6-надвиги; 7 - вулкан Эльбрус; 8- значения теплового потока, $м B \mathrm{~m} / \mathrm{M}^{2}$. I

Fig. 7. Map of the heat flow of the North Caucasus. M-b 1: 5000000 [Moiseenko, Negrov, 1993]). 1 - stations for determining the heat flux: $a$-single, $b$ - group; 2 -isolines of the heat flux, $\mathrm{mW} / \mathrm{m}^{2}: a-$ reliable, $b$-estimated; 3 - boundaries of structures; 4 -regional faults; 5 - Tyrnyauz suture zone; 6 thrusts; 7 -volcano Elbrus; 8 - heat flow values, $\mathrm{mW} / \mathrm{m}^{2}$.

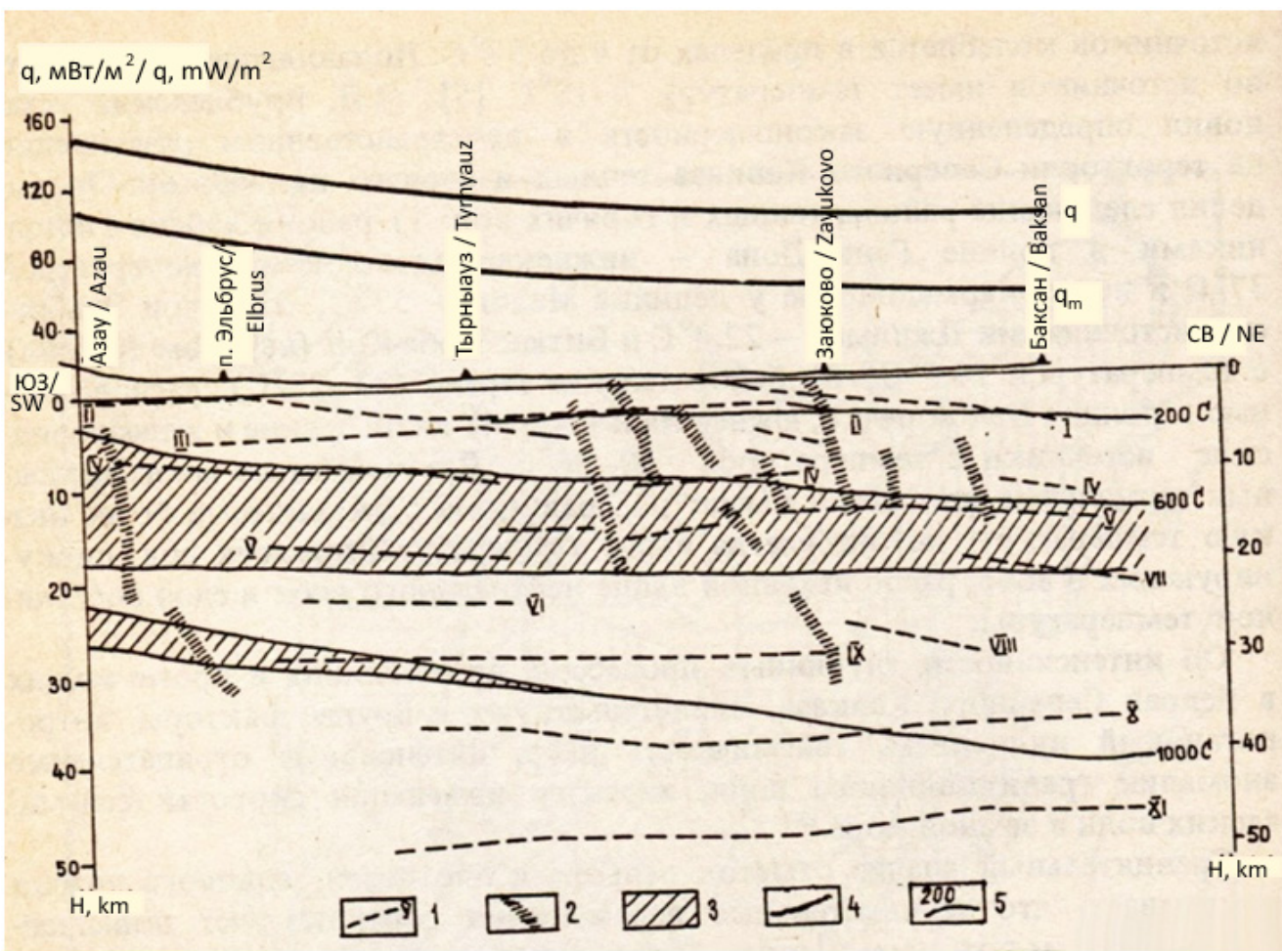

Рис. 8. Сейсмический разрез земной коры Приэльбрусья (составил А. Г. Гаркави, 1988). 
1 - границы раздела в земной коре; 2 - зоны нарушений по сейсмическим данным; 3 - слой частичного плавления; 4 - тепловой поток; 5 -изотермыл. I

Fig. 8. A seismic section of the crust of the Elbrus region (compiled by A. G. Garkavi, 1988). 1 - interface in the earth's crust; 2 - zones of violations according to seismic data; 3 - layer of partial melting; 4 - heat flow; 5 - isotherms.

Анализ всех имеющихся геолого-геофизических данных позволяет построить термомеханическую модель эволюции литосферы над поднимающимся мантийным диапиром на основе модели многослойной высоковязкой несжимаемой жидкости. Анализ полученных решений показывает, что в зависимости от соотношения между определяющими параметрами задачи (вязкости, плотности и толщины слоев, формы диапира и скорости его подъема) на дневной поверхности могут формироваться структуры сводового поднятия или депрессии [Svalova, 1992, 1993, 1997, 2002].

Если скорость подъема диапира достаточно велика или диапир поднялся близко к поверхности, то над ним формируется сводовое поднятие. Если скорость подъема невелика при достаточно толстой литосфере, то формируется структура депрессии. Глубина погружения фундамента осадочного бассейна определяется механическими, геотермическими и петрологическими факторами. При достаточной мантийной активности возможна дальнейшая смена режима прогибания на режим формирования сводового поднятия и даже излияния базальтов [Свалова, 2014].

Общая картина движений может осложняться наличием фоновых горизонтальных движений. При аналитическом решении задачи удается найти критические параметры, связывающие динамику мантийных движений с эволюцией рельефа поверхности. Построение законченной геодинамической и термомеханической модели дает возможность рассчитать поля температур и напряжений в процессе эволюции геологических структур и оценить параметры нефтегазогенерации (температурновременной индекс, окно нефтегазогенерации, термонапряжения) в динамике.

В этой связи особый интерес представляет решение обратной задачи геодинамики, когда по геолого-геофизическим данным на поверхности удается прогнозировать движение вещества на глубине.

Существует два стандартных метода решения обратных задач - метод регуляризации, когда на параметры решения накладываются дополнительные ограничения, и метод подбора, когда обратная задача решается методом решения многих прямых задач.

На основе использования асимптотических методов предлагается прямой метод решения обратной задачи геодинамики, когда использование надежных геолого-геофизических данных и скоростей на поверхности дает возможность однозначно прогнозировать движение вещества и распределение напряжений на глубине литосферы.

Рассмотрим слой высоковязкой несжимаемой жидкости, описывающей поведение вещества литосферы с помощью уравнения Навье-Стокса и уравнения неразрывности:

$$
\begin{gathered}
\frac{d \vec{v}}{d t}=\bar{F}-\frac{1}{\rho} \operatorname{gradp}+\frac{\mu}{\rho} \Delta \vec{v} \\
\operatorname{div} \vec{v}=0
\end{gathered}
$$

где $\vec{v}$ - вектор скорости, F - сила тяжести, $\mathrm{p}$ - давление, $\mathrm{r}$ - плотность, $\mu$ - вязкость, $\mathrm{t}$ - время.

Пусть характерный размер моделируемых структур по латерали L значительно превосходит характерную толщину слоя $\mathrm{h}$.

Введем безразмерные значения координат, скоростей и давления X, Y, Z, U, V, W, P:

$$
x=L X, y=L Y, z=h Z, u=u_{0} U, v=u_{0} V, w=u_{0}(h / L) W, p=r_{0} g h P .
$$


Тогда используя уравнение неразрывности и приближенное уравнение Навье-Стокса для достаточно медленных движений в тонком слое можно получить в безразмерном виде для двумерного случая [Занемонец (Свалова) и др., 1974; Svalova, 1992, 1993, 1997, 2002; Свалова, Шарков, 1991, 1992; Шарков, Свалова, 1991; Sharkov, Svalova, 2011; Свалова, 2014; Гончаров и др., 2015]:

$$
\begin{gathered}
\left\{\begin{array}{l}
\frac{\partial P}{\partial X}=\alpha \mu \frac{\partial^{2} U}{\partial Z^{2}} \\
\frac{\partial P}{\partial Z}=-\rho
\end{array}\right. \\
\frac{\partial U}{\partial X}+\frac{\partial W}{\partial Z}=0 \\
\alpha=\frac{F}{R\left(\frac{h}{L}\right)^{3}}, F=\frac{u_{0}{ }^{2}}{g L}, R=\frac{u_{0} L \rho_{0},}{\mu_{0}}
\end{gathered}
$$

где $\mathrm{P}$ - безразмерное давление, $\mathrm{U}, \mathrm{W}$ - безразмерные скорости, $\mathrm{F}$ - число Фруда, $\mathrm{R}$ число Рейнольдса, $\mathrm{r}$ - плотность, $\mu$ - вязкость, $\rho_{0}, \mu_{0}, \mathrm{u}_{0}$ - характерный масштаб плотности, вязкости и скорости.

Пусть на верхней границе поле сил равно нулю (свободная поверхность). Также пусть задано поле скоростей $\mathrm{U}^{*}, \mathrm{~W}^{*}$ на верхней границе моделирования $\varsigma^{*}$. Тогда можно найти распределение скоростей и давлений в слое:

$$
\begin{gathered}
\mathrm{P}=\rho\left(\varsigma^{*}-\mathrm{Z}\right) \\
\mathrm{U}=\mathrm{U}^{*}+\frac{\rho}{2 \alpha \mu} \frac{\partial \varsigma^{*}}{\partial \mathrm{X}}\left(\varsigma^{*}-\mathrm{Z}\right)^{2} \\
\mathrm{~W}=\mathrm{W}^{*}+\frac{\partial \mathrm{U}^{*}}{\partial \mathrm{X}}\left(\varsigma^{*}-\mathrm{Z}\right)+\frac{\rho}{2 \alpha \mu}\left[\frac{\partial^{2} \varsigma^{*}}{\partial \mathrm{X}^{2}} \frac{1}{3}\left(\varsigma^{*}-\mathrm{Z}\right)^{3}+\left(\frac{\partial \varsigma^{*}}{\partial \mathrm{X}}\right)^{2}\left(\varsigma^{*}-\mathrm{Z}\right)^{2}\right]
\end{gathered}
$$

Таким образом, по известным скоростям на поверхности определены скорости и давления на глубине, что дает возможность получить поля напряжений в слое. Полученное решение назовем решением первой обратной задачи геодинамики - нахождение скоростей, давлений и напряжений вещества на глубине по известным скоростям движения дневной поверхности.

На верхней границе должно также выполняться кинематическое условие свободной поверхности, означающее, что точки поверхности не покидают ее в процессе движения:

$$
\begin{gathered}
\mathrm{S} \frac{\partial \varsigma^{*}}{\partial \mathrm{t}}+\mathrm{U}^{*} \frac{\partial \varsigma^{*}}{\partial \mathrm{X}}-\mathrm{W}^{*}=0 \\
\mathrm{~S}=\frac{\mathrm{L}}{\mathrm{u}_{0} \mathrm{t}_{0}},
\end{gathered}
$$

где $\mathrm{S}$ - число Струхаля. $\mathrm{t}_{0}$ - характерный масштаб времени.

Аналогично можно рассмотреть нижнюю границу моделирования как поверхность, точки которой остаются на ней в процессе эволюции (условие непротекания). Тогда, подставляя скорости, получаем уравнение движения нижней границы ऽ.: 


$$
\begin{aligned}
& \mathrm{S} \frac{\partial \varsigma_{*}}{\partial \mathrm{t}}-\mathrm{W}^{*}+\mathrm{U}^{*} \frac{\partial \varsigma_{*}}{\partial \mathrm{X}}\left(\varsigma^{*}-\varsigma_{*}\right)+ \\
& +\frac{\rho}{2 \alpha \mu}\left[\frac{\partial \varsigma_{*}}{\partial \mathrm{X}} \frac{\partial \varsigma^{*}}{\partial \mathrm{X}}\left(\varsigma^{*}-\varsigma_{*}\right)^{2}-\frac{\partial^{2} \varsigma^{*}}{\partial \mathrm{X}^{2}} \frac{1}{3}\left(\varsigma^{*}-\varsigma_{*}\right)^{3}-\left(\frac{\partial \varsigma^{*}}{\partial \mathrm{X}}\right)^{2}\left(\varsigma^{*}-\varsigma_{*}\right)^{2}\right]=0
\end{aligned}
$$

Данное уравнение представляет собой прямое решение обратной задачи, когда рельеф дневной поверхности и скорости на ней определяют движение глубинных границ. Аналогичное уравнение может быть написано для любой вещественной границы на глубине, через которую отсутствует поток вещества. Назовем данное решение решением второй обратной задачи геодинамики - определение движения границы на глубине по известным скоростям поверхностных движений.

Таким образом, задавая движение дневной поверхности, мы получили скорости, давления, напряжения вещества на глубине и уравнение движения глубинных границ.

Некоторые выводы о структуре глубинных движений по известным скоростям и рельефу поверхности можно сделать, анализируя различные геологические структуры и обстановки и возможные поверхностные скорости.

Задача 1. Осадочный бассейн в условиях растяжения.

Дневная поверхность является вогнутой, т. е.:

$$
\begin{gathered}
\frac{\partial^{2} \varsigma^{*}}{\partial \mathrm{X}^{2}}>0 . \\
\operatorname{Sgn} U^{*}=\operatorname{Sgn} X
\end{gathered}
$$

Анализ решения показывает, что $\mathrm{U}$ растет с глубиной и с gradV*.

$\mathrm{W}$ соответствует восходящему потоку на глубине.

Задача 2. Осадочный бассейн в условиях сжатия.

Дневная поверхность является вогнутой, т.е.:

$$
\begin{gathered}
\frac{\partial^{2} \varsigma^{*}}{\partial \mathrm{X}^{2}}>0 . \\
\operatorname{Sgn} U^{*}=-\operatorname{Sgn} X .
\end{gathered}
$$

Анализ решения показывает, что существует критическая глубина, где горизонтальное сжатие сменяется растяжением:

$$
s_{*}=\varsigma^{*}-\sqrt{-\frac{\mathrm{U}^{*}}{\frac{\rho}{2 \alpha \mu} \frac{\partial \varsigma^{*}}{\partial X}}}
$$

Вертикальная скорость $\mathrm{W}$ может быть положительной или отрицательной в зависимости от соотношения между параметрами задачи.

Задача 3. Ороген в условиях растяжения.

Верхняя граница выпукла, т. е.:

$$
\frac{\partial^{2} \varsigma^{*}}{\partial X^{2}}<0 .
$$

$$
\operatorname{Sgn} U^{*}=\operatorname{Sgn} X .
$$


Следовательно, существует критическая глубина, где растяжение сменяется сжатием:

$$
\varsigma_{*}=\varsigma^{*}-\sqrt{-\frac{U^{*}}{\frac{\rho}{2 \alpha \mu} \frac{\partial \varsigma^{*}}{\partial X}}}
$$

Анализ величины $\mathrm{W}$ показывает возможный нисходящий поток в центре структуры на глубине. Если же растяжение на поверхности достаточно интенсивное, то на глубине возможен восходящий поток вещества.

Задача 4. Ороген в условиях сжатия.

Верхняя граница выпукла, т. е.:

$$
\begin{gathered}
\frac{\partial^{2} \varsigma^{*}}{\partial \mathrm{X}^{2}}<0 . \\
S g n U^{*}=-S g n X .
\end{gathered}
$$

В этом случае сжатие наблюдается во всем слое. Нисходящий поток вещества с большой вероятностью существует на глубине.

Следовательно, осадочный бассейн в условиях растяжения и ороген в условиях сжатия являются более стабильными и вероятными структурами, чем бассейн при сжатии и ороген при растяжении. Вывод представляется достаточно естественным, что говорит о корректности модели и возможности ее дальнейшего развития и применения.

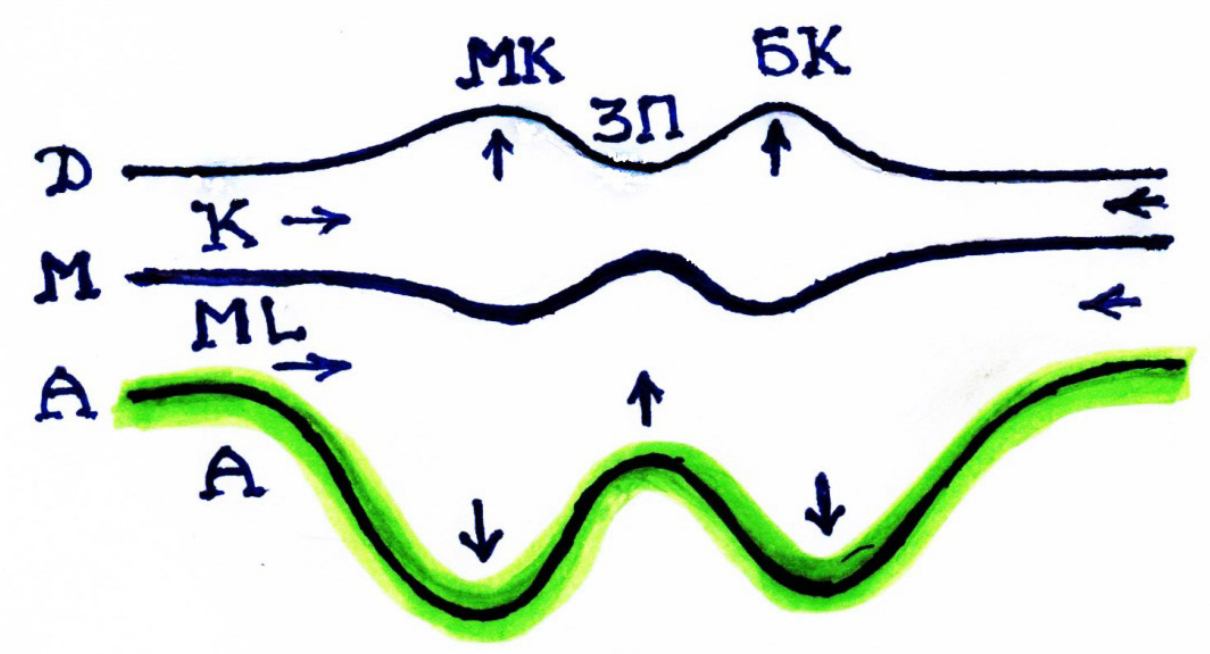

Рис. 9. Схематический разрез Кавказского региона на основе механико-математического моделирования.

$D$ - дневная поверхность, $M$ - граница Мохо, $A$ - поверхность астеносферы, $K$ - кора, $M L-$ мантийная литосфера, МК - мальй Кавказ, БК - Большой Кавказ, ЗП-Закавказский прогиб. Стрелки - возможные направления движения вещчества. /

Fig. 9. A schematic section of the Caucasus region based on mechanical and mathematical modeling. $D$ is the day surface, $M$ is the Moho boundary, $A$ is the surface of the asthenosphere, $K$ is the crust, $M L$ is the mantle lithosphere, MK is the Lesser Caucasus, BC is the Greater Caucasus, and ZP is the Transcaucasian trough. Arrows - the possible direction of motion of the substance. 


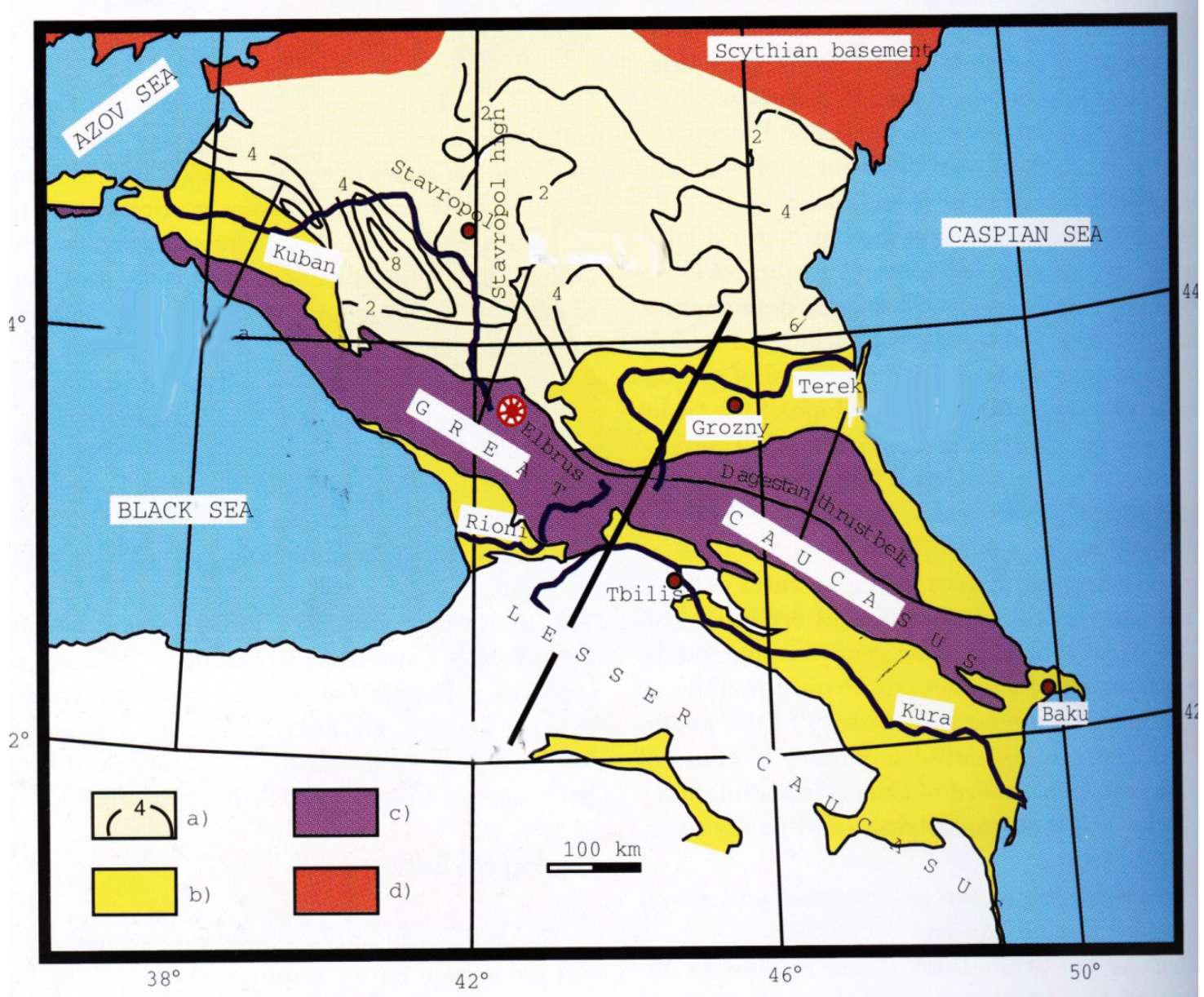

Рис. 10. Схематическая карта Кавказского региона. а) Предкавказский прогиб, b) осадочные бассейны, с) ороген, d) Скифская плита. Указано положение разреза на рисунке [Geе, Zeyen, 1996].

Fig. 10. Schematic map of the Caucasus region. a) Ciscaucasia depression, b) sedimentary basins, c) orogen, d) Scythian plate. The position of the cut is shown in Fig. [Gee, Zeyen, 1996].

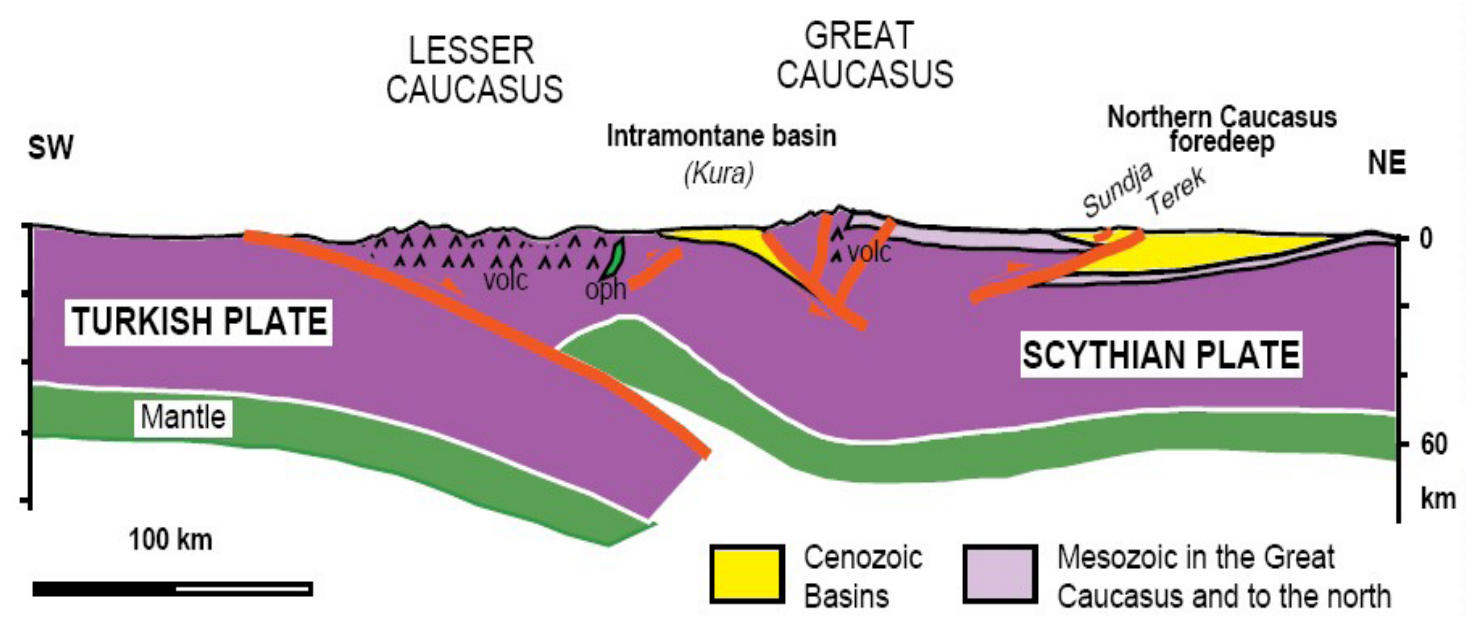

Рис. 11. Схематический разрез Кавказского региона. Положение разреза указано на рисунке 10 [Gee, Zeyen, 1996]. I

Fig. 11. A schematic section of the Caucasus region. The position of the section is shown in Figure 10 [Gee, Zeyen, 1996]. 


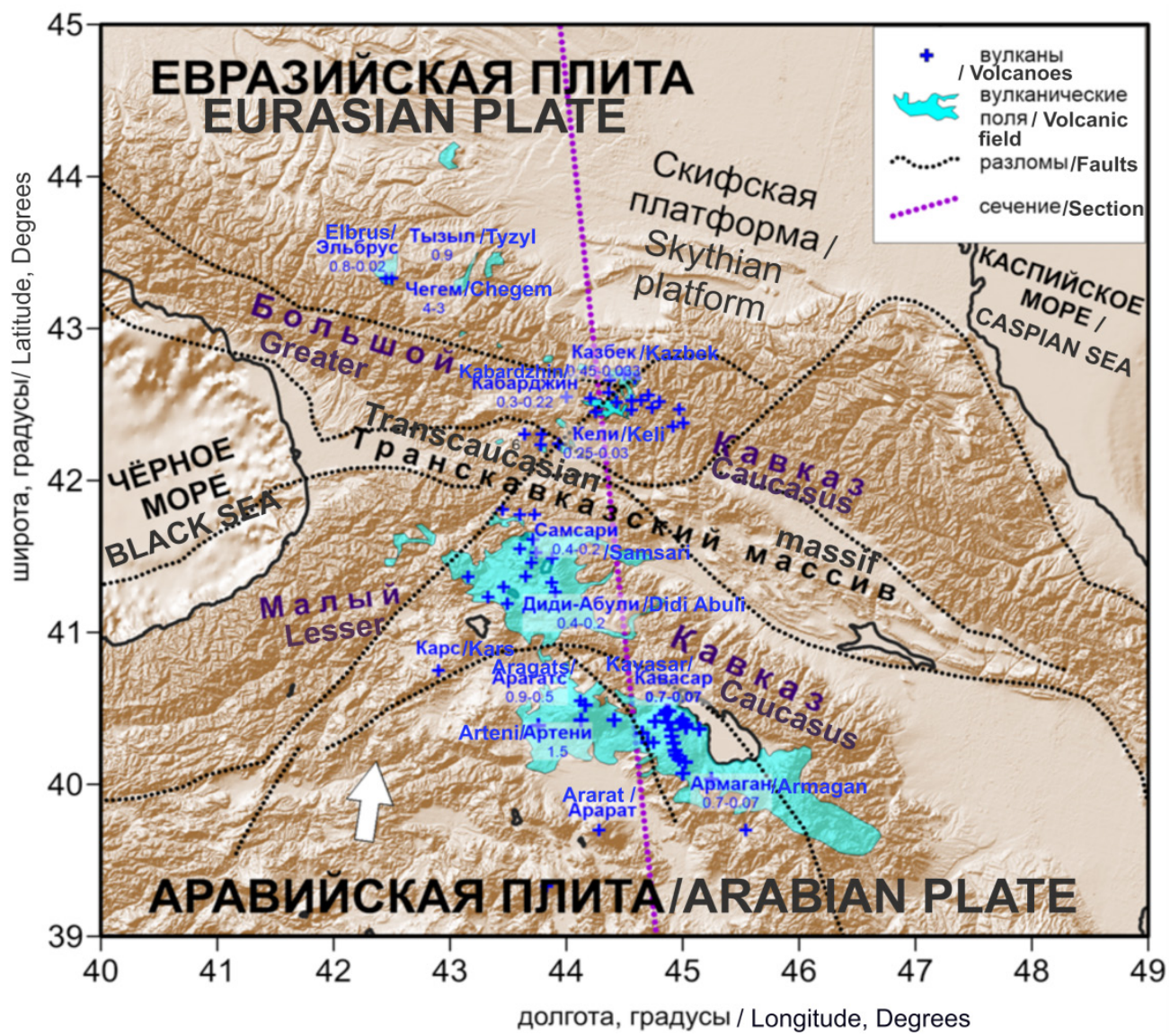

Рис. 12. Распределение кайнозойского вулканизма на территории Кавказского региона и сечение сейсмотомографического профилирования на рисунке 13 [Koulakov et al., 2012]. $/$

Fig. 12. The distribution of Cenozoic volcanism in the Caucasus region and the cross section of seismotomographic profiling in Figure 13 [Koulakov et al., 2012].

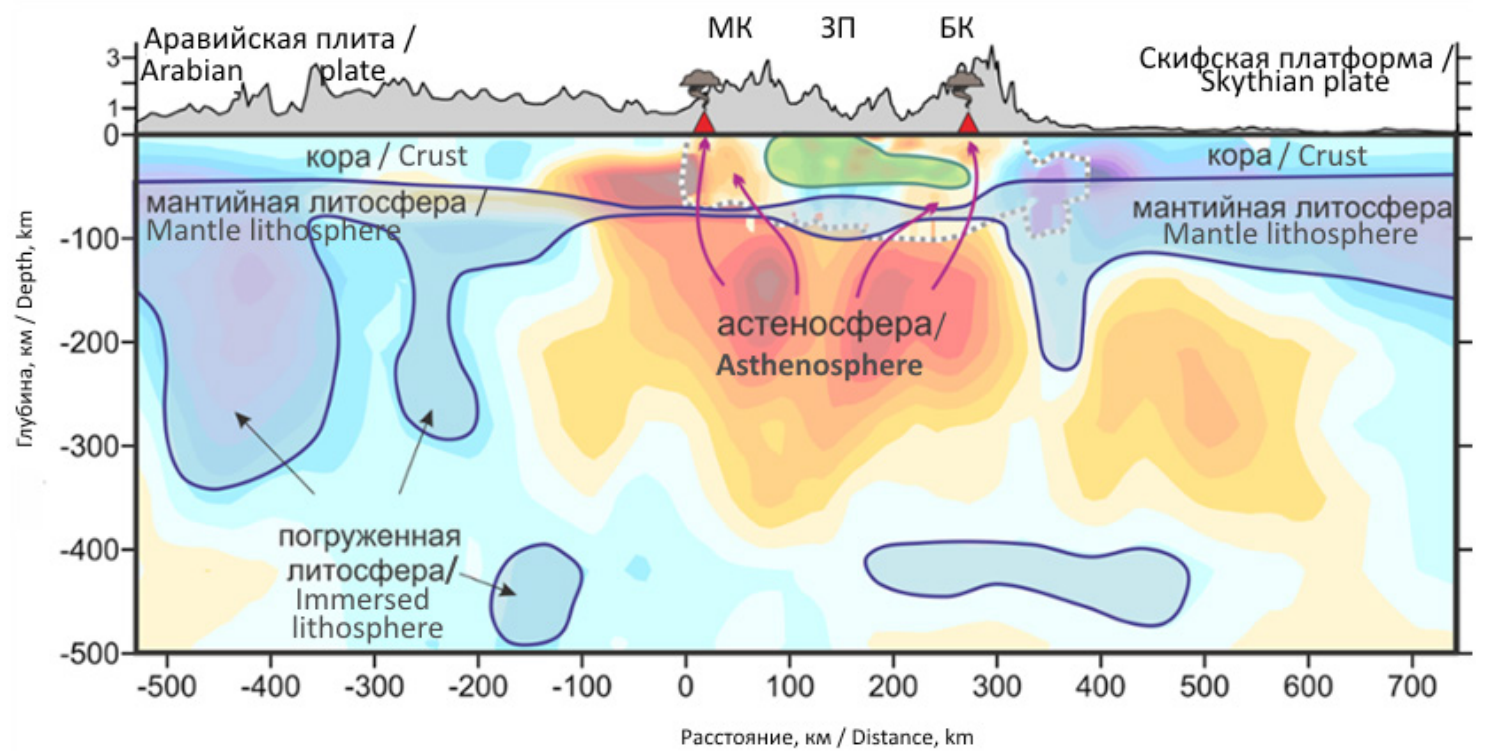

Рис. 13. Вертикальное сейсмотомографическое сечение Кавказского региона по разрезу на Рис. 12 МК, БК - Мальий и Большой Кавказ соответственно. ЗП - область Закавказского межгорного прогиба. Наверху рельеф над профилем [Koulakov et al., 2012]. I

Fig. 13. The vertical seismic tomographic section of the Caucasus region along the section in Fig. 12 $M K, B K$ - Small and Big Caucasus, respectively. ZP is the region of the Transcaucasian intermountain trough. At the top there is a relief above the profile [Koulakov et al., 2012]. 
Так, на основе анализа полученных соотношений можно говорить о наличии нисходящих движений в литосфере и погружении подошвы литосферы под горными структурами, что может иметь место в случае Кавказа.

Таким образом, в регионе Кавказа на подошве литосферы должны существовать нисходящие потоки вещества и погружение литосферы (рис. 9).

\section{5. ОбсужАение и выводы}

Таким образом, предложено и разработано решение обратной задачи геодинамики прямым методом. Решена первая обратная задача геодинамики - восстановление полей скоростей, давлений и напряжений на глубине литосферы по имеющимся данным о скоростях на дневной поверхности. Поставлена и решена вторая обратная задача геодинамики - определение движения границ на глубине литосферы по заданным движениям дневной поверхности. Полученные решения могут использоваться для анализа глубинных геодинамических проблем, а совместно с геотермическим моделированием, геолого-геофизическими методами и сейсмотомографией могут служить надежным аппаратом изучения глубинной геодинамики геологических структур и прогноза нефтегазоносности.

Вместе с тем, коллизия литосферных плит определяется и коллизией глубинных астеносферных потоков. Плиты перемещаются за счет движений в астеносфере. Геодинамика зоны коллизии астеносферных потоков определяется соотношением плотности, вязкости и температуры слоев литосферы и астеносферы. Этими же соотношениями определяется, насколько интенсивно литосферная плита перекрывает подъем астеносферы и с какой скоростью астеносферный диапир поднимается в зоне коллизии, формируя структуру задугового спрединга или утолщения астеносферы и подъема литосферы. Сложная геодинамическая картина определяется соотношением геолого-геофизических параметров и внешними ограничивающими факторами для скоростей и движений на сферической поверхности Земли и в ее глубинах.

Интересно сравнить результаты механико-математического моделирования с данными геолого-геодинамической реконструкции и сейсмотомографии (рис. 10-13).

Следует понимать, что геофизика и сейсмотомография дают глубинный разрез в настоящий момент времени, в то время как механико-математическое моделирование позволяет изучать эволюцию структуры в динамике. Сравнительный анализ различных подходов и решений дает возможность с большей надежностью делать выводы о глубинных механизмах движений и их проявлении на поверхности Земли и обосновать наиболее вероятные причины формирования и эволюции различных геологических структур и процессов.

\section{Аитература}

1. Гончаров М. А., Короновский Н. В., Свалова В. Б., Разницин Ю. Н. Вклад мантийного диапиризма в процесс формирования новообразованных впадин Средиземноморья и Карибского бассейна и окружающих центробежно-вергентных складчато-покровных орогенов. // Геотектоника. - 2015. № 6. - С. 80-93.

2. Занемонец (Свалова) В. Б., Котелкин В. Д., Мясников В.П. О динамике литосферных движений. // Изв. АН СССР. Физика Земли. - 1974. - №4 - С. 43-54.

3. Милюков В.К., Миронов А.П., Рогожин Е. А., Стеблов Г. М. Оценки скоростей современных движений Северного Кавказа по GPS наблюдениям. // Геотектоника. - 2015. - №3. - С. 56-65.

4. Моисеенко У.И., Негров О.Б. Геотермические условия Северо-Кавказской сейсмоопасной зоны. // В кн.: Геотермия сейсмичных и асейсмичных зон. - М.: Наука, 1993. - С. 32-40.

5. Рогожин Е. А., Горбатиков А. В., Степанова М.Ю., Овсюченко А.Н., Андреева Н. В., Харазова Ю.В. Структура и современная геодинамика мегантиклинория Большого Кавказа в свете новых данныхо глубинном строении. // Геотектоника. - 2015. - №2. - С. 36-49. 
6. Свалова В.Б. Механико-математическое моделирование формирования и эволюции геологических структур в связи с глубинным мантийным диапиризмом. // Мониторинг. Наука и технологии. - 2014. - №3 (20), - С. 38-42.

7. Свалова В.Б., Шарков Е.В. Формирование и эволюция задуговых бассейнов Альпийского и Тихоокеанского поясов (сравнительный анализ). // Тихоокеанская геология. - 1991. - № 5. - С. 49-63.

8. Свалова В.Б., Шарков Е.В. Геодинамика Байкальской рифтовой зоны (петрологические и геомеханические аспекты). // Геология и геофизика. - 1992. - № 5. - С. 21-30.

9. Уломов В. И., Данилова Т. И., Медведева Н. С., Полякова Т. П., Шумилина Л. С. К оценке сейсмической опасности на Северном Кавказе. // Физика земли. - 2007. - № 7. - С. 31-45.

10. Хаин В.Е., Ломизе М.Г. Геотектоника с основами геодинамики. - М.: КДУ, 2005. - 560 с.

11. Шарков Е.В., Свалова В.Б. Внутриконтинентальные моря как результат задугового спрединга при коллизии континентальных плит. // Доклады Академии наук СССР. - 1989. - Т. 308. № 3. C. 685-688.

12. Шарков Е.В., Свалова В.Б. О возможности вовлечения континентальной литосферы в процесс субдукции при задуговом спрединге. // Изв. АН СССР, сер. геол. - 1991. - № 12. - С. 118-131.

13. Gee D.G., Zeyen H.J. (editors). EUROPROBE 1996 - Lithosphere Dynamics: Origin and Evolution of Continents. // Uppsala University. - 1996. - 138 pp.

14. Koulakov I., Zabelina I., Amanatashvili I., Meskhia V. Nature of orogenesis and volcanism in the Caucasus region based on results of regional tomography. // Solid Earth. - 2012. - No. 3. - Pp. 327-337.

15. Sharkov E., Svalova V. Geological-geomechanical simulation of the Late Cenozoicgeodynamics in the Alpine-Mediterranean mobile belt. // New Frontiers in Tectonic Research - General Problems, Sedimentary Basins and Island Arcs. INTECH, Croatia. - 2011. - Pp. 18-38.

16. Svalova V.B. Mechanical-mathematical models of the formation and evolution of sedimentary basins. // Sciences de la Terre, Ser. Inf. - 1992. - No. 31. - Pp. 201-208.

17. Svalova V.B. Mechanical-mathematical simulation of geological structures evolution. // Geoinformatics. - 1993. - Vol. 4 (3). - Pp. 153-160.

18. Svalova V.B. Thermomechanical modeling of geological structures formation and evolution on the base of geological-geophysical data. // Proceedings of the Third Annual Conference of the International Association for Mathematical Geology IAMG'97, Barcelona, Spain. - 1997. - Part 2. - Pp. 1049-1055.

19. Svalova V. Mechanical-mathematical modeling for the Earth's deep and surface structures interaction. // Proceedings of International Conference IAMG, Berlin. - 2002. -5 p.

20. Svalova V.B., Zaalishvili V.B., Ganapathy G.P., Nikolaev A. V., Melkov D.A. Landsliderisk in mountain areas. // Geology of the South of Russia. - 2019. - No. 9 (2). - Pp. 109-127.

21. The Global Heat Flow Database of the International Heat Flow Comission. http://www. heatflow. und. edu/

\section{References}

1. Goncharov M.A., Koronovskii N.V., Svalova V.B., Raznitsin Yu.N. The contribution of mantle diapirism to the formation of newly formed basins of the Mediterranean and the Caribbean and the surrounding centrifugal-vergent folded-overlapped orogens. Geotectonics. 2015. No. 6. pp. 80-93. (In Russ.)

2. Zanemonets (Svalova) V.B., Kotelkin V.D., Myasnikov V.P. On the dynamics of lithospheric movements. Izv. USSR Academy of Sciences. Physics of the Earth. 1974. No. 4. pp. 43-54. (In Russ.)

3. Milyukov V.K., Mironov A.P., Rogozhin E.A., Steblov G.M. Estimates of the speeds of modern movements of the North Caucasus from GPS observations. Geotectonics. 2015. No. 3. pp. 56-65. (In Russ.)

4. Moiseenko U.I., Negrov O.B. Geothermal conditions of the North Caucasus seismic hazard zone. In the book: Geothermy of seismic and aseismic zones. M. Nauka, 1993. pp. 32-40. (In Russ.)

5. Rogozhin E.A., Gorbatikov A.V., Stepanova M.Yu., Ovsyuchenko A.N., Andreeva N.V., Kharazova $\mathrm{Yu}$.V. The structure and modern geodynamics of the meganticlinorium of the Greater Caucasus in the light of new data on the deep structure. Geotectonics. 2015. No. 2. pp. 36-49. (In Russ.)

6. Svalova V.B Mechano-mathematical modeling of the formation and evolution of geological structures in connection with deep mantle diapirism. Monitoring. Science and technology. 2014. No. 3 (20). pp. 38-42. (In Russ.) 
7. Svalova V.B., Sharkov E.V. Formation and evolution of back-arc basins of the Alpine and Pacific belts (comparative analysis). Pacific geology. 1991. No. 5. pp. 49-63. (In Russ.)

8. Svalova V.B., Sharkov E.V. Geodynamics of the Baikal rift zone (petrological and geomechanical aspects). Geology and geophysics. 1992. No. 5. pp. 21-30. (In Russ.)

9. Ulomov V.I., Danilova T.I., Medvedeva N.S., Polyakova T.P., Shumilina L.S. To the assessment of seismic hazard in the North Caucasus. Physics of the earth. 2007. No. 7. pp. 31-45. (In Russ.)

10. Khain V.E., Lomize M.G. Geotectonics with the basics of geodynamics. M. KDU, 2005. 560 p. (In Russ.)

11. Sharkov E.V., Svalova V.B. Intracontinental seas as a result of back-arc spreading during the collision of continental plates. Reports of the USSR Academy of Sciences. 1989. Vol. 308. No. 3. pp. 685-688. (In Russ.)

12. Sharkov E.V., Svalova V.B. On the possibility of involving the continental lithosphere in the subduction process during back-arc spreading. Izv. USSR Academy of Sciences, geol. ser. 1991. No. 12. pp. 118-131. (In Russ.)

13. Gee D.G., Zeyen H.J. (editors). EUROPROBE 1996 - Lithosphere Dynamics: Origin and Evolution of Continents. Uppsala University. 1996. 138 pp.

14. Koulakov I., Zabelina I., Amanatashvili I., Meskhia V. Nature of orogenesis and volcanism in the Caucasus region based on results of regional tomography. Solid Earth. 2012. No. 3. pp. 327-337.

15. Sharkov E., Svalova V. Geological-geomechanical simulation of the Late Cenozoicgeodynamics in the Alpine-Mediterranean mobile belt. New Frontiers in Tectonic Research - General Problems, Sedimentary Basins and Island Arcs. INTECH, Croatia. 2011. pp. 18-38.

16. Svalova V.B. Mechanical-mathematical models of the formation and evolution of sedimentary basins. Sciences de la Terre, Ser. Inf. 1992. No. 31. Pp. 201-208.

17. Svalova V.B. Mechanical-mathematical simulation of geological structures evolution. Geoinformatics. 1993. Vol. 4(3). pp. 153-160.

18. Svalova V.B. Thermomechanical modeling of geological structures formation and evolution on the base of geological-geophysical data. Proceedings of the Third Annual Conference of the International Association for Mathematical Geology IAMG'97, Barcelona, Spain. 1997. Part 2. pp. 1049-1055.

19. Svalova V. Mechanical-mathematical modeling for the Earth's deep and surface structures interaction. Proceedings of International Conference IAMG, Berlin. 2002. 5 p.

20. Svalova V.B., Zaalishvili V.B., Ganapathy G.P., Nikolaev A.V., Melkov D.A. Landsliderisk in mountain areas. Geology of the South of Russia. - 2019. No. 9(2). Pp. 109-127.

21. The Global Heat Flow Database of the International Heat Flow Comission. http://www.heatflow. und.edu/ 